\title{
EVIDÊNCIAS ACERCA DA GRAMATICALIZAÇÃO DE CONSTRUÇÕES COM O VERBO “ESPERAR"
}

\author{
Nathália Felix de Oliveira \\ Patricia Fabiane Amaral da Cunha Lacerda
}

\section{RESUMO}

Este trabalho tem como objetivo descrever os usos do verbo "esperar" na língua portuguesa, partindo das hipóteses de que revelariam um caminho de crescente (inter)subjetivização e de que estariam vinculados a padrôes construcionais distintos. A fim de comprovar tais hipóteses, realizou-se um levantamento sincrônico e diacrônico de dados, o qual buscou indicar quais usos identificados seriam anteriores e [-(inter)subjetivos].

PALAVRAS-CHAVE: Gramaticalização de construçôes; (Inter)subjetivização; Verbo "esperar".

\section{Introdução}

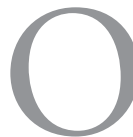

presente trabalho visa investigar pancronicamente a gramaticalização do verbo "esperar" na língua portuguesa. Para tanto, opera com as hipóteses de que, durante o seu processo de mudança linguística, "esperar" teria desenvolvido sentidos (inter)subjetivos (TRAUGOTT, 1995'; FINEGAN, $1995^{2}$;

1 TRAUGOTT, Elizabeth Closs. "Subjectification in grammaticalization". In: STEIN, Dieter; WRIGHT, Susan. Subjectivity and subjectification. New York: Cambridge University Press, 1995.

2 FINEGAN, Edward. "Subjectivity and subjectification". In: STEIN, Dieter; WRIGHT, Susan. Subjectivity and subjectification. New York: Cambridge University Press, 1995. 
TRAUGOTT \& DASHER, 2005³; TRAUGOTT, 20104) e de que esses sentidos estariam vinculados a padróes construcionais distintos (TRAUGOTT, $\left.2003^{5}, 2008^{6}, 2009^{7}\right)$.

Assim sendo, neste trabalho, defende-se que a instanciação dos diferentes usos do verbo "esperar" seria decorrente de um processo de gramaticalização. Esse processo se daria pelo mecanismo da (inter)subjetivização, o qual defende que as novas funçóes/construçóes emergentes surgem da necessidade de o falante indexar seu posicionamento diante da proposição, chegando, portanto, a significados cada vez mais subjetivos e, até mesmo, intersubjetivos. Além disso, a gramaticalização possibilitaria que as construçóes se tornassem cada vez mais integradas entre si, estabelecendo uma relação de forte dependência entre o padrão gramatical e o padrão de uso (TRAUGOTT 2003, 2008, 2009). Portanto, assume-se que o verbo "esperar" aparece vinculado a determinadas construçóes linguísticas, sendo possível identificar padróes (modelos prototípicos) diretamente relacionados aos usos identificados.

Os usuários da língua portuguesa utilizam o verbo "esperar" com diferentes usos, os quais se relacionam, como se verificará nesta pesquisa, às ideias de "aguardar no tempo", "desejar, querer" e "ter expectativa (ou não) de algo". Essa multifuncionalidade de "esperar" já foi observada por Santos $\left(2009^{8}\right)$, cujo trabalho trata pontualmente da gramaticalização desse verbo. No entan-

3 TRAUGOTT, Elizabeth Closs; DASHER, Richard. Regularity in semantic change. New York: Cambridge University Press, 2005.

4 TRAUGOTT, Elizabeth Closs. "(Inter)subjectivity and (inter)subjectification: a reassessment”. In: DAVIDSE, Kristin; VANDELANOTTE, Lieven; CUYKENS, Hubert (orgs.). Subjectification, intersubjectification and grammaticalization. Berlim/New York: De Gruyter Mouton, 2010.

5 TRAUGOTT, Elizabeth Closs. "Constructions in grammaticalization”. In: JOSEPH, Brian; JANDA, Richard (eds.). The handbook of historical linguistics. Oxford: Blackwell, 2003.

6 TRAUGOTT, Elizabeth Closs. "Grammaticalization, constructions and the incremental development of language: suggestions from the development of degree modifiers in English”. In: ECKARDT, Regine; JÄGER, Gerhard; VEENSTRA, Tonjes (eds.). Variation, Selection, Development: Probing the Evolutionary Model of Language Change. Berlin/New York: Mouton de Gruyter, 2008.

7 TRAUGOTT, Elizabeth Closs. "Grammaticalization and Construction Grammar". In: CASTILHO, Ataliba Teixeira (org.). História do Português Paulista. vol.1. Campinas: Unicamp/Publicações IEL, 2009.

8 SANTOS, Elaine Cristina Silva. Gramaticalização de verbos: o verbo 'esperar' no português culto de São Paulo. Dissertação de mestrado. São Paulo: USP, 2009. 
to, a autora se pauta em uma abordagem de gramaticalização diferente da que adotamos, visto que compreende o processo estritamente como a passagem de um item [lexical/- gramatical] > [+ gramatical] (MEILLET, 1948; ; HOPPER \& TRAUGOTT, $2008^{10}$ ). Além disso, os diferentes usos do verbo identificados pela autora estariam, segundo ela, dentro das categorias de verbo pleno, verbo quase-auxiliar e marcador conversacional, mas sem, necessariamente, se vincularem a padróes construcionais prototípicos.

Além dos três usos mencionados acima - os quais serão denominados, neste trabalho, de "esperar 1", "esperar 2" e "esperar 3" -, também foram verificadas outras construçôes em que atua o verbo "esperar". Como se verificará por meio do levantamento da frequência de uso, a construção "espera aí/perai" foi a que apresentou um maior número de ocorrências. Além dessa construção, "esperar" figura em outras sequências maiores, estabilizadas - as quais ocorrem em número bem menor nos diferentes corpora -, a saber: "(quando) (a gente/ você) menos espera", "não perde por esperar", "mal (posso) esperar", "é/era de (se) esperar", "esperar para (pra) ver".

A fim de melhor compreender esse processo, a análise se baseia, primordialmente, na metodologia qualitativa, visto que a intenção é levantar e descrever pontualmente os diferentes usos do verbo "esperar". No entanto, acredita-se que o levantamento da frequência de uso é um recurso importante para se atestarem os estágios do processo de gramaticalização. Portanto, a partir desse levantamento, a intenção é verificar quais usos do verbo "esperar" são precedentes em relação aos demais (BYBEE, 2003 ${ }^{11}$; VITRAL, 2006 ${ }^{12}$ ).

Como já mencionado, este trabalho é de cunho pancrônico, sendo a análise diacrônica fundamental para se comprovar o percurso de mudança dos usos sincronicamente atestados. Assim, os dados sincrônicos recobrem tanto a modalidade oral quanto a modalidade escrita da língua. Os dados orais foram

9 MEILLET, Antonie. Linguistique historique et linguistique générale. Paris: Champion, 1948 [1912].

10 HOPPER, Paul; TRAUGOTT, Elizabeth Closs. Grammaticalization. Cambridge: Cambridge University Press, 2008 [1993].

11 BYBEE, Joan. "Mechanisms of change in grammaticalization: the role of frequency". In: JOSEPH, Brian; JANDA, Richard (eds.). The handbook of Historical Linguistics. Oxford: Blackwell, 2003.

12 VITRAL, Lorenzo. "O papel da frequência na identificação de processos de gramaticalização”. Scripta, 9/18: 149-177, Belo Horizonte, 2006. 
coletados em três corpora distintos, a saber: o corpus do projeto "Mineirês: a construção de um dialeto", o corpus do projeto "PEUL - Programa de Estudos sobre o Uso da Língua" e o corpus do projeto NURC/RJ - Projeto da Norma Urbana Oral Culta do Rio de Janeiro. Já os dados sincrônicos escritos foram compostos por textos disponíveis na Internet retirados de blogs e de revistas de grande circulação nacional (Revista Veja, Revista Isto é, Revista Época, Revista Caras, Revista Cláudia e Revista Ana Maria). Os dados diacrônicos, por sua vez, foram selecionados do projeto "CIPM - Corpus Informatizado do Português Medieval" e do projeto "Tycho Brahe".

Inicialmente, este artigo trata dos postulados teóricos em que se baseia nossa pesquisa. Em um segundo momento, destaca a metodologia empreendida tanto na seleção/constituição dos corpora utilizados quanto na análise dos dados encontrados. Em seguida, analisa as ocorrências do verbo "esperar", evidenciando seus diferentes usos - os quais pressupóem um alinhamento entre forma e sentido - e sua distribuição nos corpora analisados. Por fim, realiza as consideraçóes finais sobre este estudo.

\section{Gramaticalização: enquadramento teórico}

Os estudos em gramaticalização, segundo Gonçalves et.al. (2007 $\left.{ }^{13}\right)$, começaram a se difundir na década de 1980 , tendo como base o trabalho de Meillet (1948). Em um primeiro momento, esse processo de mudança linguística foi concebido como a passagem de uma palavra autônoma, isto é, um item lexical para um elemento gramatical. Posteriormente, a partir dos estudos de Lehmann $\left(1995^{14}\right)$ e Heine et al. $\left(1991^{15}\right)$, a gramaticalização começou a ser considerada como um processo que envolve tanto a passagem [item lexical] $>$ [gramatical] quanto a passagem de um elemento gramatical à função [+ gramatical]. Assim, Hopper e Traugott $\left(2008,[1993]^{16}\right.$, p.103) postularam

13 GONÇALVES, Sebastião Carlos Leite et al. (orgs.). Introdução à gramaticalização. São Paulo: Parábola, 2007.

14 LEHMANN, Christian. Thoughts on Grammaticalization. Munchen, Newcastle: Lincon Europa, 1995 [1982].

15 HEINE, Bernd; CLAUDI, Ulrike; HUNNEMEYER, Friederike. Grammaticalization: a conceptual framework. Chicago: University of Chicago Press, 1991.

16 HOPPER, Paul; TRAUGOTT, Elizabeth Closs. Grammaticalization. Cambridge: Cambridge University Press, 2008 [1993]. p. 103. 
um dos clines tradicionais de mudança mais adotados: [item de conteúdo] > [palavra gramatical $]>[$ clítico $]>$ [afixo flexional $]$.

Todavia, em estudos recentes, Traugott $(1995,2010)$ e Traugott e Dasher (2005) começaram a observar as necessidades discursivas negociadas na interação - as quais, de acordo com os autores, motivariam a gramaticalização - e também reavaliaram a distinção entre item lexical e item gramatical, defendendo que qualquer elemento possui tanto propriedades gramaticais quanto discursivas e semânticas.

Assim, buscando suprir as questóes apontadas acima, Traugott (1995) introduz, no âmbito da gramaticalização, o conceito de subjetivização, o qual diz respeito ao processo semântico-pragmático de que o falante se utiliza para tornar os significados das proposiçóes cada vez mais subjetivos, ou seja, cada vez mais baseados em suas crenças e atitudes. É esse caminho que também segue Finegan (1995) ao propor que a subjetividade e o processo de criação de sentidos subjetivos - a subjetivização - refletem a expressão do self e representam o ponto de vista do falante por meio de estruturas e estratégias linguísticas.

Cabe ainda observar que, uma vez recrutados pelo falante para codificar e regular seu ponto de vista, os sentidos, que nesse momento já se encontram subjetivizados, também podem ser recrutados para codificar sentidos centrados no interlocutor, isto é, sentidos intersubjetivos. Tal fato acarreta o processo semântico-pragmático da intersubjetivização (TRAUGOTT \& DASHER, 2005, TRAUGOTT, 2010). Nesse processo, a mudança é resultante do desenvolvimento de significados que exprimem a preocupação do falante com o endereçado, isto é, com o self do interlocutor, em sentido epistêmico e social. Dessa forma, o falante está atento às atitudes do interlocutor diante do que está sendo dito.

Recentemente, Traugott $(2003,2008,2009)$, amparada teoricamente em Goldberg $\left(1995^{17}, 2006^{18}\right)$, Croft $\left(2001^{19}\right)$ e Croft e Cruise $\left(2004^{20}\right)$, também

17 GOLDBERG, Adele. Constructions: a construction grammar approach to argument structure. Chicago: University of Chicago Press, 1995.

18 GOLDBERG, Adele. Constructions at work: the nature of generalization in language. Oxford: Oxford University Press, 2006.

19 CROFT, William. Radical construction grammar: syntactic theory in typological perspective. New York: Oxford University Press, 2001.

20 CROFT, William; CRUSE, David Alan. Cognitive Linguistics. Cambridge: Cambridge University Press, 2004. 
vem adotando a perspectiva da gramaticalização de construçóes em seus estudos. A autora, nesse sentido, defende que as construções são as unidades básicas da língua, as quais - entendidas como objetos teóricos - se estabelecem, gradualmente, a partir do pareamento entre forma e sentido. Assim, a mudança ocorre na totalidade da construção e opera de maneira a estabelecer padróes construcionais mais prototípicos para determinados usos. Com isso, a gramaticalização é entendida como processos de uso da língua pelos quais ocorrem mudanças sistemáticas tanto na morfossintaxe quanto no significado (TRAUGOTT, 2008 ${ }^{21}$, p. 220). Seguindo essa perspectiva, Traugott (2009) acredita que os padróes construcionais são uma evidência a favor do grau de gramaticalizaçáo de uma determinada construção: quanto mais integrada em relaçôes sintagmáticas uma construção está, mais gramaticalizada ela é. Além disso, o trabalho com esses padróes - o qual, como já destacado, implica o alinhamento entre a estrutura da construção e o seu uso - só vem a auxiliar a abordagem da gramaticalização como (inter)subjetivização, já que esta se preocupa em não separar os aspectos tidos como estruturais dos aspectos semântico-pragmáticos.

Baseando-nos no que foi exposto, advogamos que o verbo "esperar", na língua portuguesa, passou por um processo de (inter)subjetivizaçáo no desenvolvimento de novos usos, os quais, em contextos específicos, através da ritualização, foram incorporados à gramática da língua - desenvolvendo padróes construcionais prototípicos -, sendo, portanto, gramaticalizados.

\section{Metodologia}

A análise, nesta pesquisa, desenvolve-se a partir da perspectiva pancrônica, a qual alinha as metodologias sincrônica e diacrônica. Nesse sentido, além de se investigarem as construçóes gramaticais enquanto um fenômeno discursivo-pragmático - observando os diferentes estágios linguísticos -, realiza-se um exame sobre a origem e a trajetória dessas construções - verificando a incorporação da mudança na gramática. Esse posicionamento metodológico

21 TRAUGOTT, Elizabeth Closs. "Grammaticalization, constructions and the incremental development of language: suggestions from the development of degree modifiers in English”. In: ECKARDT, Regine; JÄGER, Gerhard; VEENSTRA, Tonjes (eds.). Variation, Selection, Development: Probing the Evolutionary Model of Language Change. Berlin/New York: Mouton de Gruyter, 2008. p. 220. 
corrobora o defendido por Furtado da Cunha, Oliveira e Votre (199922), que evidenciam a forte tendência em se consolidar a pancronia em estudos funcionalistas, principalmente em se tratando de gramaticalização. Assim sendo, temos como principal objetivo desenvolver uma análise sincrônica, identificando e descrevendo os diferentes padrôes funcionais de "esperar" no português contemporâneo e, a partir de uma análise diacrônica, buscar elucidar, com maior propriedade, quais usos seriam anteriores e [- (inter)subjetivos].

Os dados sincrônicos se distribuem de maneira a constituir dois corpora distintos, a saber: um referente à modalidade oral e o outro referente à modalidade escrita. $\mathrm{Na}$ oralidade, trabalhamos com três diferentes corpora bastante abrangentes: a) o corpus do "Projeto Mineirês: a construção de um dialeto", ${ }^{23}$; b) o corpus do PEUL/RJ (Programa de Estudos sobre o Uso da Língua) ${ }^{24}$; e amostras da década de 1970 e 1990 do NURC/RJ (Projeto da Norma Urbana Oral Culta do Rio de Janeiro ${ }^{25}$. Por sua vez, os corpora sincrônicos escritos foram distribuídos em três níveis de formalidade ${ }^{26}$, sendo utilizados, para tanto, textos de blogs e revistas, os quais circulam na internet e datam do início do século XXI. Nesse sentido, os níveis de formalidade se organizam da seguinte forma:

Quadro 1 - Organização dos níveis de formalidade dos corpora escritos sincrônicos

\begin{tabular}{|l|l|}
\hline Nível de formalidade & \multicolumn{1}{c|}{ Descrição } \\
\hline Nível de formalidade 1 & $\begin{array}{l}\text { Textos publicados em blogs pessoais que tratam sobre } \\
\text { assuntos cotidianos }\end{array}$ \\
\hline Nível de formalidade 2 & $\begin{array}{l}\text { Textos publicados em revistas que observam questóes } \\
\text { diárias e mais triviais (as revistas selecionadas foram: } \\
\text { Ana Maria, Caras e Cláudia) }\end{array}$ \\
\hline Nível de formalidade 3 & $\begin{array}{l}\text { Textos publicados em revistas que tratam de assuntos } \\
\text { com maior impacto em termos nacional e internacional } \\
\text { (as revistas selecionadas foram: Veja, Isto é e Época) }\end{array}$ \\
\hline
\end{tabular}

22 FURTADO DA CUNHA, Maria Angélica; OLIVEIRA, Mariângela Rios de; VOTRE, Sebastiāo. "A interaçấo sincronia/diacronia no estudo da sintaxe". DELTA [online], http:// www.scielo.br/scielo.php?script=sci_arttext\&pid=S0102-44501999000100004\&lng=en\& nrm=iso, Acessado em 21/08/2011, 15/1: s/p., 1999.

23 Disponível em http://www.letras.ufmg.br/mineires/. Acessado em 12/11/2010.

${ }^{24}$ Disponível em http://www.letras.ufrj.br/peul/. Acessado em 15/01/ 2011.

25 Disponível em http://www.letras.ufrj.br/nurc-rj/. Acessado em 03/03/ 2011.

26 A noção de formalidade adotada nesta pesquisa advém da perspectiva da variação diafásica (do grego: dia + phasis = "através de" + "discurso"), a qual diz respeito à variação linguística observada na fala de um mesmo indivíduo ocasionada pelas condiçóes extraverbais que cercam o ato de fala. 
Já os dados diacrônicos foram reunidos a partir de textos escritos tanto do português europeu quanto do português do Brasil. Esses textos - mais especificamente textos ficcionais e documentos notariais - foram selecionados do "CIPM" (Corpus Informatizado do Português Medieval) ${ }^{27}$ e do projeto "Tycho Brahe" ${ }^{28}$ e recobrem o período entre os séculos XIII e XIX.

Um dos critérios utilizados para a seleção/constituição dos corpora foi a manutenção da uniformidade no número de palavras. Nesse sentido, cada corpus sincrônico utilizado - tanto na modalidade oral quanto na modalidade escrita - é composto por 300 mil palavras (totalizando um milhão e oitocentas mil palavras para a sincronia), como se verifica no quadro abaixo:

Quadro 2 - Total de número de palavras analisadas por corpus na sincronia

\begin{tabular}{|c|l|c|}
\hline \multirow{3}{*}{ Modalidade Oral } & \multicolumn{1}{|c|}{ Corpus } & $\begin{array}{c}\text { Total de palavras } \\
\text { analisadas }\end{array}$ \\
\cline { 2 - 3 } & $\begin{array}{l}\text { "Projeto Mineirês: a construção } \\
\text { de um dialeto" }\end{array}$ & 300.000 \\
\cline { 2 - 3 } & Projeto "PEUL" & 300.000 \\
\cline { 2 - 3 } & Projeto "NURC/RJ" & 300.000 \\
\hline \multirow{3}{*}{ Modalidade Escrita } & Nível de formalidade 1 & 300.000 \\
\cline { 2 - 3 } & Nível de formalidade 2 & 300.000 \\
\cline { 2 - 3 } & Nível de formalidade 3 & 300.000 \\
\cline { 2 - 3 } & \multicolumn{1}{|c|}{ Total } & $\mathbf{1 . 8 0 0 . 0 0 0}$ palavras \\
\hline
\end{tabular}

No que se refere aos dados diacrônicos, cada século é composto por 100 mil palavras (totalizando 700 mil palavras para a diacronia), como se visualiza no quadro a seguir:

Quadro 3 - Total de número de palavras analisadas nos corpora diacrônicos

\begin{tabular}{|l|c|}
\hline \multicolumn{1}{|c|}{ Século } & Total de palavras analisadas \\
\hline Século XIII & 100.000 \\
\hline Século XIV & 100.000 \\
\hline Século XV & 100.000 \\
\hline Século XVI & 100.000 \\
\hline Século XVII & 100.000 \\
\hline Século XVIII & 100.000 \\
\hline Século XIX Total & 100.000 \\
\hline & $\mathbf{7 0 0 . 0 0 0}$ palavras \\
\hline
\end{tabular}

27 Disponível em http://cipm.fcsh.unl.pt/. Acessado em 20/01/2011.

28 Disponível em http://www.tycho.iel.unicamp.br/-tycho/. Acessado em 25/02/2011. 
Tal uniformidade no número de palavras é relevante, visto que, se estamos operando com o levantamento da frequência de uso, é necessário - para que se evitem possíveis enviesamentos, ou seja, assimetrias no levantamento de tal frequência - que cada corpus apresente o mesmo tamanho, mesmo que aproximadamente (VITRAL, 2006).

A partir da seleção/constituição dos dados, realizamos uma análise qualitativa das ocorrências encontradas do verbo "esperar". Isso porque tivemos o intuito de levantar e descrever, pontualmente, os diferentes usos do verbo "esperar", bem como seus possíveis padróes construcionais.

\section{Análise dos dados}

Como já destacado neste trabalho, foram identificados, nos corpora analisados, três diferentes usos para o verbo "esperar". O primeiro, denominado nesta pesquisa de "esperar 1", refere-se à ideia de "aguardar no tempo"; o segundo, "esperar 2", diz respeito à manifestaçãao da volição do falante; e o terceiro, "esperar 3", expressa as expectativas ou contraexpectativas do falante. A seguir, tratamos de “esperar 1".

(1) [...] na hora de saí mesmo de dá tchau dispidi por um ano da minha família foi assim bem difícil e:: aqueles últimos abraços chorei bastante cheguei dentro do avião choranu fui até São Paulo choranu e e u vôu de BH até São Paulo foram só foi só uma hora de vôu mas eu tive que ficar em São Paulo esperando seis horas porque o meu vôu pru Panamá demorava bastante e lá enquanto isso essas seis horas eu fui passear pelo aeroporto liguei pra minha família aqui de Minas Gerais pra conta que tava tudo bem entrei na interne::t conheci umas mininas da da França que tavam voltanu ("Projeto Mineirês", entrevista $15-\mathrm{BH})$

Em (1), o entrevistado está relatando a sua viagem para o Panamá e, através de um adjunto adverbial de tempo ("seis horas"), expressa o tempo que teve de aguardar para embarcar, no aeroporto de São Paulo. Neste caso, o verbo "esperar" possui o significado de "aguardar no tempo". 
Como defendemos neste trabalho, "esperar 1" atualiza a noção aspectual de duratividade, em que se evidencia o desenvolvimento da ação. Segundo Travaglia $\left(2006^{29}\right.$, p. 40), aspecto é

[...] uma categoria verbal de TEMPO, não dêitica, através da qual se marca a duração da situação e/ou suas fases, sendo que estas podem ser consideradas sob diferentes pontos de vista, a saber: o do desenvolvimento, o do completamento e o da realização da situação. (TRAVAGLIA, 2006, p. 40)

O autor prossegue suas consideraçóes sobre a aspectualidade, destacando que a duratividade - assim como outras noçóes aspectuais - pode se manifestar linguisticamente por meio de alguns modos/tempos verbais e de algumas formas nominais em particular. De acordo com o autor, a forma nominal do gerúndio é, essencialmente, durativa. Em nossos dados, ela foi mais frequente sincronicamente (35\% das ocorrências) e, na diacronia, foi a segunda mais frequente (19\% das ocorrências). Os exemplos seguem abaixo:

(2) Como adorno, a noiva usou uma tiara em ouro rosê com pérolas rosadas de água doce confeccionada por Rosana Negrão (46), anel Bulgari e brincos de diamantes. Esperando por Iolanda, estava o seu amado em um impecável terno Versace. A cerimônia foi realizada por dom Marcelo Daniel Goldstein (48), da igreja Católica e Apostólica Tradicional no Brasil, do Itaim Bibi. (Revista Caras)

(3) Saiu-se fora da tenda o bom velho, e tornou à sua ermida, e o infante esperando pelo sinal prometido, gastou em oração afervorada todo o espaço da noite até a segunda vigia, na qual ouviu o som da campainha. (Século XVI, Antônio Brandão)

Em (2), temos que o gerúndio indica a duratividade da situação: aguardar a noiva no altar da igreja. No mesmo sentido, temos a ocorrência (3), em

29 TRAVAGLIA, Luiz Carlos. O aspecto verbal no português: a categoria e sua expressão. $4^{\mathrm{a}}$ ed. Uberlândia: EDUFU, 2006. 
que se evidencia o processo de espera pelo som da campainha. Dessa forma, o gerúndio, prototipicamente, marca a noçâo de duratividade em "esperar 1 ”. Observa-se, claramente, através destes exemplos, que o gerúndio indica situaçóes em progresso, que se realizam continuamente dentro de um limite temporal.

Por sua vez, defendemos que o verbo "esperar", ao passar por um processo de mudança semântico-pragmática, desenvolveu um sentido [+ subjetivo] relacionado à expressão da volição do falante, classificado, nesta pesquisa, como "esperar 2".

(4) E (entrevistador): assim, é: pro seu futuro, assim, que que você espera, sei lá, seja lá pra o ano 2000 mesmo agora pra esse ano, é: e todos os outros que virão assim, diga uma coisa boa que você acha que, sabe? tá faltando na sua vida que você tem fé que vai mudá e tal, cê é uma pessoa assim, otimista? Cê tem muitos planos?

F (falante): Tê mais é responsabilidade, eu espero que eu seja mais responsável, tenha mais responsabilidade e aí eu...Vai vê se as coisa muda mais pra mim (est). (“PEUL”, entrevista T06)

A partir do julgamento que realiza, o falante, em (4), projeta seus desejos para o ano 2000, expressando, assim, o que quer mudar, no que se refere a suas características pessoais. O verbo "esperar", neste caso, é usado para expressar a volição do falante, marcando, dessa forma, sua vontade, sua intenção ou seu desejo em relação a um fato possível.

Ao analisarmos "esperar 1", vimos que a noção aspectual, mais precisamente a duratividade, é atualizada na utilização do verbo "esperar" com o sentido de "aguardar no tempo". Logo, acreditamos que, ao passar pelo processo de gramaticalização, o "esperar" volitivo deixa de atualizar aspecto, passando a ser utilizado com um uso modal. Com isso, defendemos, nesta pesquisa, que "esperar 2", ao se gramaticalizar: a) restringe (bloqueia) a atualização do aspecto; e b) relaciona-se ao desejo de realização de uma situação futura. Além dessas duas características, verificamos, tanto nos dados sincrônicos quanto nos dados diacrônicos, que "esperar 2" apresenta, prototipicamente, uma oração encaixada finita como complemento (correspondendo a 65,3\% do total de ocorrências sincrônicas e $58 \%$ do total de ocorrências diacrônicas). A alta 
frequência desse padrão evidencia, como acreditamos, a regularização desse par forma-sentido. $\mathrm{O}$ exemplo a seguir demonstra esse possível padrão construcional.

(5) Essa questão do ser completo, muito pela individualidade de cada um, assim, eu e Deise, nós nos casamos. Existe ela, a pessoa dela, a individualidade dela, as coisas dela, as amigas dela, eu nunca vou me metê no que ela vai fazer, eu não me meto, de maneira nenhuma, da mesma forma que espero que ela não se meta nas minhas coisas, no meu... Sabe? ("PEUL”, entrevista R07)

Na ocorrência acima, "esperar 2" apresenta como complemento a oração finita "que ela não se meta nas minhas coisas". Esse complemento evidencia a vontade/desejo do falante de que sua individualidade seja respeitada pela esposa.

Neste trabalho, defendemos que o verbo “esperar" também se gramaticalizou em um uso que marca a expressão de uma determinada expectativa do falante, bem como uma expectativa que é rompida/quebrada de maneira que não se confirme. Essa última situação revela o que Heine et al. (1991) chamam de contraexpectativa. Em ambas as situações, "esperar 3" indica crenças do falante (ou atribuídas por ele a alguém) diante daquilo que ele acredita ser possível, mesmo que essa crença não se confirme posteriormente, correspondendo, portanto, a um uso [+ subjetivo] do verbo em relação ao "esperar 1". As ocorrências (6) e (7) ilustram essa "dupla" característica de "esperar 3":

(6) Se o ritmo de crescimento de passageiros de primeira viagem for mantido com a expansão econômica do país, até a Copa o número de novatos será ainda maior. Mas Marçal Goulart, superintendente de Gestáo Operacional da Empresa Brasileira de Infraestrutura Aeroportuária (Infraero) afirma que os aeroportos das cidades-sedes serão melhorados, para atender os novos passageiros, os antigos e os estrangeiros. "Esperamos um crescimento de $30 \%$ no movimento das principais pistas, mas descarto completamente a possibilidade de um novo caos aéreo durante a Copa." (Revista Isto é)

Em (6), diante do crescente aumento de passageiros nos aeroportos brasileiros, o superintendente da Infraero anseia que, na Copa do Mundo, a qual 
será realizada no país em 2014, haverá um aumento de 30\% no movimento das principais pistas do Brasil. Assim, seja diante daquilo que se acredita, ou seja diante de fatos, o falante cria determinadas expectativas, as quais podem ser comprovadas ou não. $\mathrm{O}$ verbo "esperar", nesta acepção, refere-se às expectativas do falante acerca do que diz.

(7) Em grande estilo, o Paulínia Festival de Cinema fez a alegria dos cineastas brasileiros no encerramento de sua quarta edição, no Theatro Municipal da cidade, a $120 \mathrm{~km}$ de SP. Com a amada, Bruna Lombardi (58), Carlos Alberto Riccelli (65) ficou emocionado ao ouvir o seu terceiro trabalho atrás das câmeras, Onde Está a Felicidade?, ser anunciado o Melhor Longa de Ficção pelo Júri Popular. "Não esperávamos esse prêmio, que é o maior que se poderia receber", garante ele. "É ótimo ver o carinho do público e ainda vencer nessa categoria", emenda Bruna, que, além de estrelar o filme, assina a produção e o roteiro. (Revista Caras)

$\mathrm{Na}$ ocorrência acima, o falante, diante da avaliação que realizou, aponta que não tinha a expectativa de receber um prêmio pelo trabalho cinematográfico desenvolvido. Logo, houve uma quebra da expectativa que se criou.

Em nossos dados, verificamos que "esperar 3" se realiza mais frequentemente para indexar as expectativas do falante (correspondendo a 60,4\% das ocorrências sincrônicas e 75,9\% das ocorrências diacrônicas). No que concerne ao padrão construcional deste uso, realizaremos algumas consideraçóes.

Heine et al. propóem que a noção de contraexpectativa implica a expressão do "contraste entre aquilo que corresponde e aquilo que desvia das normas e padróes característicos do mundo com o qual o falante está familiarizado, tem em mente ou acredita que o interlocutor tem em mente, em contexto específico" (1991 ${ }^{30}$, p.192). Segundo os autores, aquilo que corresponde às normas compartilhadas - ou seja, às expectativas - não apresenta nenhuma marcação gramatical. Por outro lado, as situaçóes que desviam das normas compartilhadas apresentam o que os autores chamam de marcadores de contraexpectativa. $\mathrm{O}$ uso desses marcadores acarreta uma comparação entre aquilo

30 HEINE, Bernd; CLAUDI, Ulrike; HUNNEMEYER, Friederike. Grammaticalization: a conceptual framework. Chicago: University of Chicago Press, 1991. 
que era "esperado" e aquilo que foi dito. Em nossos dados, os marcadores de contraexpectativa encontrados foram os seguintes: (i) a negação da expectativa - atribuindo um valor adversativo ao enunciado -; (ii) a comparação entre a expectativa e aquilo que realmente se sucedeu; ou (iii) a utilização de ambos os recursos.

No entanto, Martelotta $\left(1998^{31}\right)$ frisa que o contraste entre aquilo que se tem em mente (muitas vezes, como sendo algo compartilhado pelo interlocutor) e aquilo que realmente acontece nem sempre é tấo evidente. $\mathrm{O}$ autor destaca que, em muitos casos, as expectativas não são as mesmas para falante e ouvinte ou, até mesmo, não há uma norma ou um padráo estabelecido de maneira que se possa suscitar uma expectativa. Nesse sentido, Martelotta $\left(1998^{32}\right.$, p. 41) defende que a expectativa pode derivar do próprio texto, de modo que a contraexpectativa surge para evitar possíveis interpretaçóes/inferências que o interlocutor possa realizar. No caso específico de "esperar 3", verificamos que o falante se baseia em expectativas que ele assume e que acredita já terem sido criadas pelo interlocutor. Desse modo, a marcação que antes acompanhava o verbo passa a figurar nas cláusulas que o sucedem, quebrando a possível expectativa do interlocutor, como se verifica em (8):

(8) Lew afirmou que "já há coisas acontecendo" nos esforços para alcançar um acordo, desde a reunião na quinta-feira entre Obama e parlamentares do governo e da oposição na Casa Branca. Obama havia dito que esperava ouvir dos líderes sobre uma saída para o problema por volta do fim de semana, mas o sábado passou, e não houve anúncio de uma nova reunião na Casa Branca. (Revista Veja)

Em (8), ao se dizer que o presidente Obama tinha a expectativa de que soluçóes fossem apresentadas pelos líderes para a crise no governo por volta do fim de semana, cria-se a imagem de que tais soluçóes aparecerão. Contudo, a oração subsequente, introduzida pelo conectivo adversativo "mas", rompe com essa expectativa, afirmando que não houve nenhum pronunciamento da Casa Branca até o sábado. Desse modo, como se verifica, a contraexpectativa

31 MARTELOTTA, Mário Eduardo. "Gramaticalização e graus de vinculação sintática em cláusulas concessivas e adversativas". Revista Veredas, 2/2: 37-56, 1998.

32 MARTELOTTA, Mário Eduardo. "Gramaticalização e graus de vinculação sintática em cláusulas concessivas e adversativas". Revista Veredas, 2/2: 37-56, 1998. 
é introduzida a partir da presença de uma oração adversativa subsequente à oração em que figura o verbo "esperar". Assim, a contraexpectativa se dá de maneira que "esperar 3" figure em uma cláusula, marcando a crença do falante (ou a quem a crença está sendo atribuída), e a oração adversativa se manifeste posteriormente, introduzindo a ruptura de uma possível inferência equivocada a partir do que foi dito.

Ainda no que se refere ao possível padrão construcional de "esperar 3", verificamos - através das ocorrências analisadas - a alta produtividade do pretérito imperfeito do indicativo (73,7\% de ocorrências sincrônicas e $61,9 \%$ de ocorrências diacrônicas). As contraexpectativas, em sua maioria, reportam situaçôes em que as expectativas concebidas anteriormente foram rompidas. Logo, aquilo que o falante tinha em mente é tido como pano de fundo: as expectativas do falante que são quebradas revelam o que ele já trazia consigo.

A partir dos apontamentos realizados, temos que "esperar 3" revela como padrão prototípico a náo marcação linguística da noção de expectativa e a presença do pretérito imperfeito do indicativo e de certos marcadores para a expressão de contraexpectativa, mesmo que essa marcação se dê no decorrer do discurso.

Além dos usos referentes a "esperar 1", "esperar 2" e "esperar 3", foram verificadas outras construções em que figura o verbo "esperar". Das construçôes encontradas, a que apresentou maior frequência de uso, como se verificará na tabela 1, foi "espera aí/peraî". Essa construçấo, constituída pelo verbo "esperar" junto com o advérbio "ấ", revela uma multifuncionalidade, sinalizando um pedido de tempo propriamente dito por parte do falante (como em (9)), bem como organizando o discurso, o que revela a preocupação do falante frente ao seu interlocutor. Neste último caso, apresenta um sentido [+ intersubjetivo], visto que opera como marcador discursivo: tanto para sinalizar uma necessidade de tempo para que se possa (re)formular o discurso, como em (10), quanto para codificar um ponto de vista contrário do falante diante de uma situação ou informação, como em (11).

(9) E qual a escola que você frequentou?

(Segunda interferência)

NP! Ta boa?

Olá ! Tudo bem? 
Continuação

NP é a NP. Espera aí deixa eu atender aqui. ("Projeto Mineirês", entrevista 11, Arceburgo)

(10) E: De qual jogador jogador do Flamengo você mais gosta?

F: Ah, espera aí, deixa eu vê... Romário, tem o (inint.), mas agora ele saiu do Flamengo.

E: Edmundo não é mais do Flamengo não?

F: Não. Edmundo é do Vasco. ("PEUL”, entrevista R08)

(11) Por exemplo, se eu vou na Brahma, peço a Brahma pra investir no meu filme, a Brahma vai e me dá quinhentos mil reais pra ajudar eu a fazer o filme. Eu vou na:... outras coisas aí, começo a captar o dinheiro bastante, e no final não faz filme. E pra onde foi esse dinheiro? Aí eles começam a pressionar o Ministério da Cultura:: "Olha, eu investi naquele filme lá, até agora não saiu o filme, por quê?”. Aí eles tem que dar o detalhe de tudo, quanto gastou de tudo, e não bate. Não tá batendo, entendeu? Por exemplo, o meu marido também trabalha em cinema e ele disse que um desses filme aí desse cara, é: (hes) eles botaram lá que pra uma mulher pentear uma peruca oito mil reais que ela cobrou (risos). Tu acha isso? Pera aí, é brincadeira com a cara do povo, é brincadeira. Pentear uma peruca oito mil reais. Eles fazem isso pensando que a pessoa é um otário, é um palhaço, entendeu? Que vai cair naquilo ali. Pô, então eu acho que eles têm que ser severo em dar dinheiro. ("PEUL", entrevista R01)

Primeiramente, temos que, em (9), o falante realiza um pedido de tempo para que possa atender ao telefone. Nesse caso, o tempo solicitado não está relacionado à necessidade de se organizar o discurso, mas sim à necessidade de se realizar uma outra atividade, de modo que a conversa seja interrompida. Por sua vez, em (10), o falante sinaliza para seu interlocutor que precisa pensar na resposta para a pergunta feita. Dessa maneira, preenche o vazio acarretado por tal necessidade, demonstrando sua preocupação interacional e, posteriormente, oferece o nome de jogador do Flamengo de quem mais gosta, respondendo, portanto, a pergunta. Já (11) reflete um contexto altamente argumentativo, em que o falante critica a apropriação ilícita de determinados 
produtores, que se utilizam do dinheiro concedido pelo governo para a produção de filmes nacionais em benefício próprio. Assim, ao contestar o alto faturamento dos produtores - relatando o suposto gasto de oito mil reais com a atividade de "pentear uma peruca" -, o falante introduz sua avaliaçâo. Nesse sentido, "perai" funcionaria como a manifestação de um posicionamento do falante, relacionando aquilo que vem sendo exposto - que não é de acordo com o que o falante pensa - à inserção do ponto de vista acerca de tal fato.

Além da construção "espera aí/peraí”, encontramos, em menor frequência, outras construçóes em que figura o verbo "esperar". Oferecemos abaixo um quadro em que as apontamos e as exemplificamos:

Quadro 4 - Outras construções em que figura o verbo "esperar"

\begin{tabular}{|l|l|}
\hline $\begin{array}{l}\text { (Quando) (a gente/ } \\
\text { você) menos espera }\end{array}$ & $\begin{array}{l}\text { (12) Você se acostuma a não ficar na defensiva e, quan- } \\
\text { do menos espera, leva uma bela rasteira da vida. Eu } \\
\text { vivo sempre em alerta, em estado de atençáo. (Revista } \\
\text { Cláudia) }\end{array}$ \\
\hline Não perde por esperar & $\begin{array}{l}\text { (13) Tô tratano ela bem demais! Agora, tamém ela num } \\
\text { perde por esperá o que vem, né? ("PEUL", entrevista } \\
\text { T12) }\end{array}$ \\
\hline Mal (posso) esperar & $\begin{array}{l}\text { (14) Fiquei sabendo que minha vó e minha mãe compra- } \\
\text { ram chocolate pra me dar de páscoa quando eu voltar, } \\
\text { mal posso esperar hihi. (blog http://sendointercambi- } \\
\text { sta.blogspot.com/) }\end{array}$ \\
\hline É/era de (se) esperar & $\begin{array}{l}\text { (15) Agora, realmente Paris, eu, achei já bem mais } \\
\text { movimentado, como era de se esperar. (NURC/RJ, } \\
\text { entrevista 48) }\end{array}$ \\
\hline Esperar para (pra) ver & $\begin{array}{l}\text { (16) Segundo ela, o site criado por J.K.Rowling para o } \\
\text { anúncio de um novo produto ligado a Harry Potter deve } \\
\text { se transformar no endereço de um game sobre o bruxi- } \\
\text { nho. É esperar para ver. (Revista Veja) }\end{array}$ \\
\hline
\end{tabular}

Tais construçóes correspondem a sequências maiores, estabilizadas, em que o verbo "esperar" estabelece uma relação de integridade com os outros elementos que a compóem para que se vincule um determinado sentido. Assim, "(quando) (a gente/ você) menos espera", "não perde por esperar", "mal (posso) esperar", "é/era de (se) esperar”, "esperar para (pra) ver” revelam um 
julgamento do falante frente ao que diz, um comentário avaliativo acerca da situação descrita.

Com base nas considerações realizadas até o momento, disponibilizamos, inicialmente, uma tabela com a distribuição dos diferentes usos do verbo "esperar" nos corpora sincrônicos:

Tabela 1 - Distribuição do verbo "esperar" nos corpora sincrônicos analisados

\begin{tabular}{|c|c|c|c|c|c|c|c|c|c|c|c|c|}
\hline & \multicolumn{2}{|c|}{ Esperar 1} & \multicolumn{2}{|c|}{ Esperar 2} & \multicolumn{2}{|c|}{ Esperar 3} & \multicolumn{2}{|c|}{\begin{tabular}{|c|} 
Constru- \\
ção espera \\
aí/peraí
\end{tabular}} & \multicolumn{2}{|c|}{$\begin{array}{c}\text { Outras } \\
\text { constru- } \\
\text { ções com } \\
\text { esperar }\end{array}$} & \multirow[t]{2}{*}{ Total } \\
\hline & & n..$^{\circ}$ & $\%$ & n..$^{\circ}$ & $\%$ & n..$^{\circ}$ & $\%$ & n. ${ }^{\circ}$ & $\%$ & n. ${ }^{\circ}$ & $\%$ & \\
\hline \multirow{3}{*}{ 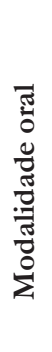 } & $\begin{array}{c}\text { Corpus } \\
\text { do Projeto } \\
\text { Mineirês }\end{array}$ & 60 & $70,6 \%$ & 6 & $7 \%$ & 9 & $10,6 \%$ & 9 & $10,6 \%$ & 1 & $1,2 \%$ & 85 \\
\hline & $\begin{array}{l}\text { Corpus do } \\
\text { Projeto } \\
\text { PEUL }\end{array}$ & 61 & $65,6 \%$ & 13 & $14 \%$ & 5 & $5,4 \%$ & 12 & $12,9 \%$ & 2 & $2,1 \%$ & 93 \\
\hline & $\begin{array}{l}\text { Corpus do } \\
\text { Projeto } \\
\text { NURC-RJ }\end{array}$ & 27 & $50,9 \%$ & 12 & $22,6 \%$ & 5 & $9,4 \%$ & 8 & $15,1 \%$ & 1 & $2 \%$ & 53 \\
\hline \multirow{3}{*}{ 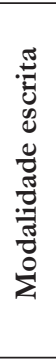 } & $\begin{array}{c}\text { Nível de } \\
\text { formalidade } \\
1\end{array}$ & 71 & $34,3 \%$ & 94 & $45,4 \%$ & 32 & $15,5 \%$ & 0 & $0 \%$ & 10 & $4,8 \%$ & 207 \\
\hline & $\begin{array}{c}\text { Nível de } \\
\text { formalidade } \\
2 \\
\end{array}$ & 64 & $50,4 \%$ & 34 & $26,8 \%$ & 26 & $20,5 \%$ & 0 & $0 \%$ & 3 & $2,3 \%$ & 127 \\
\hline & $\begin{array}{c}\text { Nível de } \\
\text { formalidade } \\
3\end{array}$ & 32 & $32,6 \%$ & 43 & $43,9 \%$ & 19 & $19,4 \%$ & 0 & $0 \%$ & 4 & $4,1 \%$ & 98 \\
\hline & Total & 315 & $47,5 \%$ & 202 & $30,5 \%$ & 96 & $14,5 \%$ & 29 & $\begin{array}{l}4,4 \% \\
\end{array}$ & 21 & $3,1 \%$ & 663 \\
\hline
\end{tabular}

Primeiramente, ao analisarmos a tabela acima, podemos notar que os usos sincrônicos do verbo "esperar" encontram-se distribuídos em um total de 663 ocorrências. É possível verificarmos que a maior parte dessas corresponde ao verbo "esperar" com o sentido de "aguardar no tempo". Assim, ("esperar 1 "). totaliza 315 ocorrências dentro do universo mencionado, o que corresponde a $47,5 \%$. Já "esperar 2", isto é, o uso volitivo, aparece como o segundo mais frequente (202 ocorrências), com 30,5\% do total da frequência de uso. Em seguida, temos "esperar 3", o qual diz respeito à expressão das expectativas 
ou não do falante, totalizando 96 ocorrências e correspondendo, nesse sentido, a $14,5 \%$ do total. A construção "espera aî"/"peraî" diz respeito a 4,4\% das ocorrências, isto é, ocorre 29 vezes nos corpora sincrônicos analisados. Já as outras construçóes em que o verbo "esperar" figura totalizam 3,1\% das ocorrências, correspondendo, portanto, a 21 ocorrências.

Realizadas as consideraçóes sobre os dados sincrônicos, passamos para a descrição da frequência dos usos identificados no corpus diacrônico, buscando observar sua distribuição. Para tanto, será disponibilizada, logo abaixo, uma tabela.

Tabela 2 - Distribuição do verbo "esperar" nos corpora diacrônicos analisados

\begin{tabular}{|c|c|c|c|c|c|c|c|c|c|c|c|}
\hline & \multicolumn{2}{|c|}{ Esperar 1} & \multicolumn{2}{|c|}{ Esperar 2} & \multicolumn{2}{|c|}{ Esperar 3} & \multicolumn{2}{|c|}{$\begin{array}{c}\text { Construção } \\
\text { espera aíl } \\
\text { peraí }\end{array}$} & \multicolumn{2}{|c|}{$\begin{array}{c}\text { Outras } \\
\text { construções } \\
\text { com esperar }\end{array}$} & \multirow[t]{2}{*}{ Total } \\
\hline & n. ${ }^{\circ}$ & $\%$ & n. ${ }^{\circ}$ & $\%$ & n..$^{\circ}$ & $\%$ & n. ${ }^{\circ}$ & $\%$ & n. ${ }^{\circ}$ & $\%$ & \\
\hline $\begin{array}{c}\text { Século } \\
\text { XIII }\end{array}$ & 1 & $100 \%$ & 0 & $0 \%$ & 0 & $0 \%$ & 0 & $0 \%$ & 0 & $0 \%$ & 1 \\
\hline $\begin{array}{c}\text { Século } \\
\text { XIV }\end{array}$ & 4 & $100 \%$ & 0 & $0 \%$ & 0 & $0 \%$ & 0 & $0 \%$ & 0 & $0 \%$ & 4 \\
\hline $\begin{array}{c}\text { Século } \\
\text { XV }\end{array}$ & 4 & $40 \%$ & 5 & $50 \%$ & 1 & $10 \%$ & 0 & $0 \%$ & 0 & $0 \%$ & 10 \\
\hline $\begin{array}{c}\text { Século } \\
\text { XVI }\end{array}$ & 12 & $52,2 \%$ & 1 & $4,3 \%$ & 8 & $34,8 \%$ & 0 & $0 \%$ & 2 & $8,7 \%$ & 23 \\
\hline $\begin{array}{c}\text { Século } \\
\text { XVII }\end{array}$ & 27 & $23,3 \%$ & 47 & $40,5 \%$ & 42 & $36,2 \%$ & 0 & $0 \%$ & 0 & $0 \%$ & 116 \\
\hline $\begin{array}{l}\text { Século } \\
\text { XVIII }\end{array}$ & 18 & $33,3 \%$ & 11 & $20,4 \%$ & 24 & $44,4 \%$ & 0 & $0 \%$ & 1 & $1,9 \%$ & 54 \\
\hline $\begin{array}{c}\text { Século } \\
\text { XIX }\end{array}$ & 34 & $58,6 \%$ & 12 & $20,7 \%$ & 12 & $20,7 \%$ & 0 & $0 \%$ & 0 & $0 \%$ & 58 \\
\hline Total & 100 & $37,6 \%$ & 76 & $28,6 \%$ & 87 & $32,7 \%$ & 0 & $0 \%$ & 3 & $1,1 \%$ & 266 \\
\hline
\end{tabular}

A partir da análise das 266 ocorrências diacrônicas do verbo "esperar", observamos que, nos séculos XIII e XIV, o verbo apresenta somente a acepção de "aguardar no tempo" ("esperar 1"), sendo encontrada, no século XIII, somente 1 ocorrência do verbo e, no século XIV, 4 ocorrências. No século 
$\mathrm{XV}$, temos que os usos volitivo (“esperar 2”) e manifestação da expectativa ou não do falante ("esperar 3") passam a ocorrer. Em um total de 10 ocorrências do verbo "esperar", neste século, 4 correspondem a "esperar 1" (40\%), 5 a "esperar 2" (50\%) e 1 a "esperar 3" (10\%). Em relação ao século XVI, temos que este totaliza 23 ocorrências, distribuindo-se do seguinte modo: "esperar 1 ” ocorre 12 vezes (52,2\%), “esperar 2" manifesta-se somente 1 vez (4,3\%), "esperar 3" aparece 8 vezes $(34,8 \%)$ e - inserindo um novo padrão de uso - a construção "(quando) (a gente) menos espera” ocorre 2 vezes $(8,7 \%)$. Já no século XVII, o verbo torna-se bastante recorrente na língua - principalmente em relação aos seus usos [+ subjetivos] -, totalizando 117 ocorrências. Os usos "esperar 2" e "esperar 3" estão bem difundidos, apresentando, respectivamente, $47(40,5 \%)$ e 42 (36,2\%) ocorrências. Já “esperar 1” apresenta 27 ocorrências $(23,3 \%)$. Para o século XVIII, encontramos 54 ocorrências do verbo "esperar", distribuídas da seguinte forma: 18 ocorrências para "esperar 1 ” (33,3\%), 11 ocorrências para "esperar 2" (20,4\%), 24 ocorrências para "esperar 3" (44,4\%) e 1 ocorrência de "(quando) (a gente) menos espera" $(1,9 \%)$. Por fim, no século XIX, verificamos 58 ocorrências do verbo, sendo 34 ocorrências para "esperar 1 " $(58,6 \%)$ e 12 ocorrências tanto para "esperar 2" quanto para "esperar 3" (20,7\%).

Observando a frequência de uso do verbo "esperar" entre os diferentes séculos, em um total de 266 ocorrências, temos: a) 100 ocorrências para "esperar 1"; b) 76 ocorrências para "esperar 2"; c) 87 ocorrências para "esperar 3"; d) nenhuma ocorrência para a construção "espera aí/peraí"; e d) 3 ocorrências de "esperar" em outras construçóes.

Com isso, temos que o levantamento da frequência de uso do verbo "esperar", tanto sincrônica quanto diacronicamente, forneceu um indício para acreditarmos que o verbo em questão desenvolveu sentidos [+ intersubjetivos] durante seu processo de mudança, visto que:

(i) tanto no que se refere à diacronia quanto à sincronia, e diante do fato de ser o único uso encontrado nos séculos XIII e XIV, "esperar 1" corresponde à acepção mais basilar do verbo;

(ii) por ocorrerem somente a partir do século XV e por serem menos frequentes sincrônica e diacronicamente do que "esperar 1", os usos [+ subjetivos] do verbo "esperar" - "esperar 2" e "esperar 3" - mostram-se ser posteriores no processo de mudança; 
(iii) devido à não-ocorrência nos dados diacrônicos e à baixa frequência nos dados sincrônicos, a construção "espera aí/peraî" corresponde a um uso bastante recente na língua.

A partir do exposto, verificamos o processo de mudança semântico-pragmática percorrido pelo verbo "esperar". No entanto, os desenvolvimentos dos diferentes sentidos abordados acima - "aguardar no tempo", "voliçáa", "ter expectativa (ou não)" - estão relacionados a possíveis padrōes construcionais, como viemos reiterando neste trabalho.

\section{Considerações finais}

Este trabalho teve por objetivo investigar o processo de gramaticalização do verbo "esperar" na língua portuguesa. Assim sendo, identificou, sincronicamente, três usos para o verbo, os quais foram também averiguados na diacronia, sendo possível, através desta e da frequência de uso, atestar qual seria a acepção inicial de "esperar", bem como seus sentidos gramaticalizados. Além desses usos, também observamos a ocorrência do verbo "esperar" em outras construçôes específicas.

Partimos das hipóteses de que os usos gramaticalizados do verbo "esperar" revelariam um caminho de crescente (inter)subjetivização e se manifestariam, mais prototipicamente, por meio de padróes construcionais. Tais hipóteses, como demonstramos neste trabalho, foram confirmadas. Assim, chegamos ao cline de mudança que partiu do uso [- subjetivo] para usos [+ subjetivos]. Logo, [“esperar 1"] > ["esperar 2" / "esperar 3"].

Vimos que, ao longo do tempo, o verbo "esperar", que inicialmente apresentava a acepção de "aguardar no tempo", se desenvolveu e passou a expressar volição e expectativas/contraexpectativas. Para tanto, deixou de atualizar a noção aspectual de duratividade e, no caso do seu sentido volitivo, passou a projetar o futuro através de um padrão construcional mais prototípico que engloba o verbo "esperar" (preferencialmente na primeira pessoa do indicativo) e uma oração encaixada finita. Já em relação à expressão das (contra)expectativas, vimos que somente ao indexar as quebras e rupturas das expectativas do falante o verbo "esperar" (preferencialmente no pretérito imperfeito do indicativo) age junto a elementos de valor negativo, comparativo ou adversativo. 
Também foram encontradas outras construções em que figura o verbo "esperar". Durante nosso trabalho, atribuímos um maior destaque à construção "espera aí/peraî" devido ao maior número de ocorrências - embora esse ainda seja pequeno - em relação às outras construções verificadas. Defendemos que essas construçóes constituem sequências maiores que se estabilizam na língua, através de seu constante emprego dentro da comunidade linguística, de maneira a configurar um padrão recorrente e produtivo.

Conforme pudemos atestar, o verbo "esperar", a partir de uma reanálise semântico-pragmática, desenvolveu usos [+ (inter)subjetivos], os quais são utilizados em diferentes situaçóes comunicativas pela comunidade linguística, a depender daquilo que se "quer" dizer.

\title{
EVIDENCES ABOUT THE GRAMMATICALIZATION OF CONSTRUCTIONS WITH THE VERB “ESPERAR"
}

\begin{abstract}
This paper intends to describe uses of the verb "esperar" in the Portuguese language, by assuming the hypothesis that the new grammaticalized uses would reveal an increasing way of (inter)subjectification. And it also assumes that this process would be related to the emergence of possible constructional patterns. In order to prove these hypotheses, we also accomplished a synchronic and diachronic survey that tried to demonstrate which uses would be earlier and [- (inter)subjective].
\end{abstract}

KEYWORDS: Grammaticalization of constructions; (Inter)subjectification; Verb "esperar".

Recebido em: 15/01/2013

Aprovado em: 05/08/2013 